Research Article

\title{
Designing and Simulation of Permanent Magnet Synchronous Generator for Wind Energy Hybrid System
}

\author{
Shoaib Khan ${ }^{1}$, Sida Hussain ${ }^{2}$, Amir Naveed ${ }^{1 *}$, Nazia Wali ${ }^{3}$, Zafar Ullah ${ }^{1}$, Muhammad Arif ${ }^{1}$, Muhammad \\ Sadiq $^{4}$ and Muhammad Asif ${ }^{5}$
}

${ }^{1}$ Center for Advanced Studies in Energy Engineering, University of Engineering and Technology, Peshawar, Khyber Pakbtunkbwa, Pakistan; 'Department of Civil Engineering, University of Engineering and Technology, Peshawar, Khyber Pakhtunkhwa, Pakistan; ${ }^{3}$ Faculty of Computing, Riphah International University, Islamabad, Pakistan; ${ }^{4}$ Department of Mechanical Engineering, University of Engineering and Technology, Peshawar, Khyber Pakhtunkhwa, Pakistan; ${ }^{5}$ Department of Electronics, University of Peshawar, Khyber Pakhtunkhwa, Pakistan.

\begin{abstract}
Renewable energy technologies are the main focus in today's world for scientists and engineers due to global climate issues. Energy extracted from wind and solar are the two most established ones as more than $5 \%$ of electricity is produced from wind globally. This paper gives insight knowledge to the energy planners for developing a cost-effective way to mitigate the electricity problems in low-income areas by incorporating the energy mix of wind and solar. A Surface Mounted Permanent Magnet Synchronous Generator is designed for the location and simulated in Matlab. With a fixed rated speed of $100 \mathrm{rpm}$, based on the load calculation, the number of poles and slots calculated are 60 and 180 respectively. The total load demand is shared $50 \%$ between wind and solar as per the load demand of the locality. The total capacity of the generator designed is $60 \mathrm{~kW}$. Sensitivity analysis of the designed machine is done by varying the hyper-parameters of the wind turbine generators.

Received: November 27, 2020; Accepted: June 19, 2021; Published: June 30, 2021

*Correspondence: Amir Naveed, Center for Advanced Studies in Energy Engineering, University of Engineering and Technology, Peshawar, Khyber Pakhtunkhwa, Pakistan; Email: amirkhattak@uetpeshawar.edu.pk

Citation: Khan, S., S. Hussain, A. Naveed, N. Wali, Z. Ullah, M. Arif, M. Sadiq and M. Asif. 2021. Designing and simulation of permanent magnet synchronous generator for wind energy hybrid system. Journal of Engineering and Applied Sciences, 40(1): 52-59.

DOI: https://dx.doi.org/10.17582/journal.jeas/40.1.52.59

Keywords: Permanent magnet synchronous generator, Doubly fed induction generator, Wound rotor induction generator, Squirrel cage induction generator, Technique of order preference similarity to ideal solution
\end{abstract}

\section{Introduction}

The worldwide increasing environmental 1 and ecological constraints resulted from the extraction of energy from fossil fuels with its limited availability in the future (Herbet et al., 2007), has compelled the world policymakers on renewables to look for alternate resources of energy. Besides the depletion of fossil fuels, the environmental concerns due to the emission of $\mathrm{CO}_{2}$ gas, which has its role in Global Warming and other toxic gases are some of the major restraints that have highlighted the energy demand from the non-conventional resources (Chiari et al., 2011). Renewable energy exists in the form of solar, wind, hydro, biomass, geothermal, and tidal energy in nature (Alrikabi, 2014). If only wind energy is taken into account as this paper would deal, then it is important to understand the scientific reason behind the existence of wind on earth's atmosphere as it is only possible to get feasible energy out of the wind on earth's atmosphere where wind speed is sustainable to rotate the wind turbine. The different weather patterns resulted from the uneven terrain on the earth's surface and geographical tilt causes different heat conditions 
near the surface of the earth from the sun that causes the wind to blow from higher atmospheric pressure to lower atmospheric pressure (Herbet et al., 2007). According to the multi-criteria decision analysis (Saleem and Ulfat, 2019), conducted for the different alternatives for the household domestic sector in Pakistan, wind energy is ranked the second most feasible alternative for the household energy demand sector. In Permanent Magnet Synchronous Generator (PMSG) was designed for $1500 \mathrm{~W}$ rated power (Hebala et al., 2017). In this paper, the PMSG Wind turbine generator is designed for $60 \mathrm{~kW}$ rated power and its simulation is done by using Matlab Simulink software. The structure of this paper is categorized as follows: The ratings/specifications of the generator along with the comparative analysis between different topologies of generators consisting of the Squirrel Cage Induction Generator (SCIG), Doubly Fed Induction Generator (DFIG), and Permanent Magnet Synchronous Generator (PMSG) are studied in section I. The type of generator with the highest performance is considered for the locality along with its topology. The methodology of the designed machine is explained in section II. The designed machine sensitivity is evaluated against its calculated parameters in the result and analysis section III. In the end, the conclusion has been highlighted in section IV.

\section{Rating/specification of wind generator}

The design of the Generator from the Wind Turbine is based on 100 houses in a locality. The maximum load demand in the location is in the summer season where the average load demand is $39 \mathrm{kWh}$ for the six months of the summer season and the average load demand for the winter season is $15.6 \mathrm{kWh}$. Based on the location of Pakistan the design system of the Renewable Energy System is a hybrid one with an addition of solar PV and will be Grid-connected (Baloch et al., 2019). The rating of the wind generator is such that $75 \%$ of the total load demand is divided into a 50\% share, between the solar PV and the Wind Energy system. Since the design is made for the summer season and the maximum average load in the month of summer is calculated from Table 1 , as $39 \mathrm{kWh} \times 0.75 \times 0.5=14.625 \mathrm{kWh}$ per day. The load in $\mathrm{kW}$ is calculated as $14.625 / 24=0.61 \mathrm{~kW}$ and for the 100 homes, the total load calculated demand is $0.61 \times 100=61 \mathrm{~kW}$.

The power factor is roughly taken as unity; since the power converters will nullify all the reactive power as all the power transformer is an active power in "Watts" so the generator power in $\mathrm{kVA}$ same as $61 \mathrm{kVA}$.

Table 1: Load calculation.

\begin{tabular}{lllll}
\hline Months & $\begin{array}{l}\text { Total load } \\
\text { per day } \\
\text { (Wh) }\end{array}$ & $\begin{array}{l}\text { Actual Load (Wh) } \\
\text { per day for the } \\
\text { wind energy }\end{array}$ & $\begin{array}{l}\text { Days } \\
\text { Total Load } \\
\text { in one year } \\
\text { (Wh) }\end{array}$ \\
\hline Jan & 15600 & 5850 & 31 & 181350 \\
Feb & 15600 & 5850 & 28 & 163800 \\
Mar & 15600 & 5850 & 31 & 181350 \\
Apr & 39000 & 14625 & 30 & 438750 \\
May & 39000 & 14625 & 31 & 453375 \\
Jun & 39000 & 14625 & 30 & 438750 \\
Jul & 39000 & 14625 & 31 & 453375 \\
Aug & 39000 & 14625 & 31 & 453375 \\
Sep & 39000 & 14625 & 30 & 438750 \\
Oct & 15600 & 5850 & 31 & 181350 \\
Nov & 15600 & 5850 & 30 & 175500 \\
Dec & 15600 & 5850 & 31 & 181350 \\
Average & 327600 & 122850 & 365 & 3741075 \\
\hline
\end{tabular}

\section{Tradeoff between different topologies on the type of generators}

In the case of grid-associated short circuit faults, the SCIG is more superior to DFIG due to its detachability option from the grid. In DFIG 30\% of the output power passes via a power converter making it advantageous as low-cost power converters can also be used (Beainy et al., 2016). In the case of altogether effectiveness, robustness, and longevity the direct-drive PMSG system is more superior on offshore sites (Beainy et al., 2016). The power specification determined for a load demand of 100 homes is $61 \mathrm{~kW}$. Based on the classification of wind turbine technologies, the design of the wind turbine generator will fall in the medium-size category, with a generator type as Permanent Magnet Synchronous Generator (Patil et al., 2013).

\section{Selection of machine topology}

In terms of high reliability, low cost, technical maturity a surface-mounted PM generator is considered to be the best choice according to TOPSIS analysis (Gupta and Singh, 2016). A surface-mounted PM generator has a typical configuration where the magnets are affixed at the top surface of the rotor, hence the name 'Surface Mounted Permanent Magnet' (SMPM) machine. In this setup to balance the centrifugal force, the magnets are affixed to the rotor surface. The orientation of magnets is made in the radial direction but least common in the circumferential direction. 
The reactance in the quadrature and direct directions are almost the same. Due to simple rotor contour, amongst other configurations, the construction of the rotor core is the easiest in SMPM (Madani et al., 2015). The surface-mounted configuration is shown below. Due to simple rotor geometry, the nonsalient surface-mounted permanent magnet topology is selected to lessen the overall cost of the machine (Madani et al., 2015). In the non-salient machine, the quadrature axis inductance and direct axis inductance are both equal since the permeability of free air is almost equivalent to the permeability of a permanent magnet.

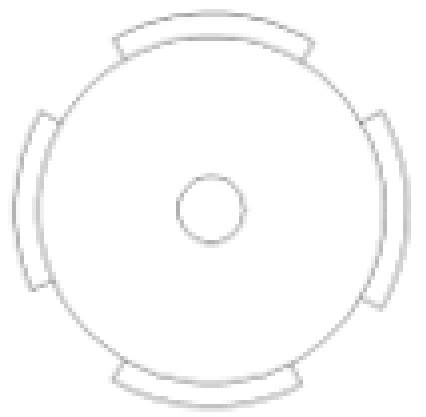

Figure 1: A Surface mounted rotor for a PMSG.

\section{Windings}

The windings generally use are Distributed Winding, Concentrated Winding, Fractional Slot Winding, and Single Layer Concentrated Non-Overlapping Winding. In terms of efficiency for low-speed applications such as wind turbines, concentrated windings are more efficient to be used (Ghoneim et al., 2016). A Surface mounted rotor for a PMSG and Matlab Simulink design of PMSG are shown in Figure 1 and 3, respectively.

\section{Materials and Methods}

\section{Design of a selected machine}

The design flow chart is shown in Figure 2.

The following constants like the winding factor $K_{w}$, tooth flux density $B_{t}$, remnant flux density $B_{r}$, Stator flux density $B_{s}$ and lamination filling factor $K_{\text {fil }}$ is taken from the literature review (Hebala et al., 2017; Ghoneim et al., 2016). The methodology of the designed machine has been incorporated in the flow chart. The design of the generator has been evaluated in excel also given in the appendix section. The novelty of the design is based on modifying the slot depth and its dimensions until a difference in magnitude of the area of slot calculated through iteration and area of slot evaluated by equation $A_{c s} / K_{\text {fill }}$ reaches the minimum value of $5 \%$ of $A_{s}$ (area of slot). Consequently, the magnet thickness, stator inner/ outer radii, rotor inner/outer radii, air-gap length, and Stack length all change with the modifications based on the size of the PMSG wind turbine generator.

Set design requirements

$\&$ constraints regarding

speed of generator and load demand
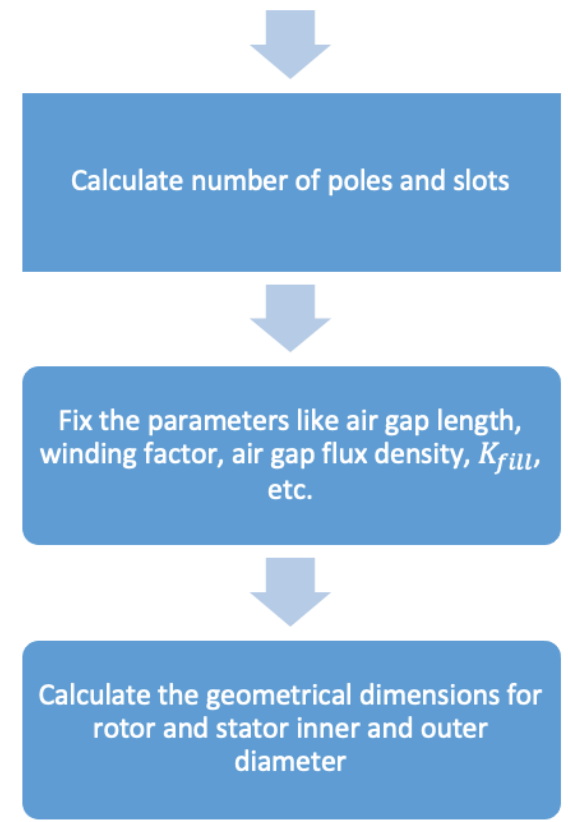

Calculate the parameters like pole pitch, slot depth, $A_{s}$ Area of slot calculated by $A_{c s} / K_{f i l l}$. Area of slot calculated based on actual dimensions

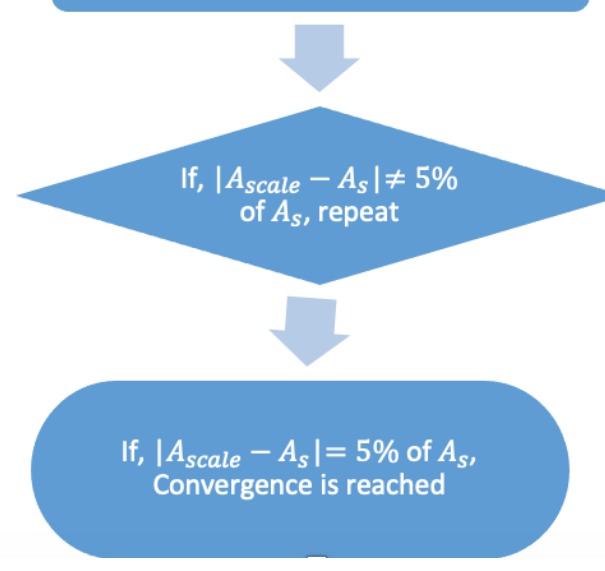

Figure 2: Design flow chart.

\section{Results and Discussion}

The Matlab Simulink diagram is made after setting the speed at a rated value of $100 \mathrm{rpm}$, (Madani 
et al., 2015). A Low pass (LC) filter is added after rectification to remove higher harmonics while smoothing the curve. The values of inductance and capacitance are set to the values of $50 \times 10^{-6} \mathrm{H}$ and $50 \times 10^{-6} F$ respectively. The input torque defined by the step input to the PMSG block is readjusted with a step time given at 0.2 while limiting the simulation to a 1-time unit. Average load demand per day calculation for a building apartment for winter and summer seasons as shown in Supplementary Table 2.

The input torque to the generator is calculated as:

Torque $=\frac{\text { Calculated load, } \mathrm{Pm}}{\text { Angulare Speed of Rotor in Rad/Sec }}=\frac{60,000}{(2 \pi / 60) \times 100}=5729.74 \mathrm{Nm}$

Resistance of stator, Armature Inductance, Flux linkage, and pair of poles are found to be:

The Resistance of the stator $R$, is calculated as;

$$
R_{s}=\frac{\rho L}{A}
$$

Where $p$ is the resistivity of the copper $\left(1.77 \times 10^{-8}\right), L$ is the Stack length and $A$ is the area of the conductor, using Equation 1, putting the values calculated in the excel sheet from Supplementary Table 1:

$$
\begin{gathered}
R_{s}=\frac{1.77 \times 10^{-8} \times \text { Stack lenght } \times N_{p h}}{\frac{\pi D c^{2}}{4}} \\
R_{s}=\frac{1.77 \times 10^{-8} \times 1.095 \times 60}{\frac{\pi 0.0044^{2}}{4}} \\
R_{s}=0.3 \Omega / \text { phase }(2)
\end{gathered}
$$

With the addition of $1.92 \Omega$ resistance of the connector and $1.92 \Omega$ resistance of the junction the total resistance of the stator becomes:

$$
\begin{gathered}
R_{s}=0.31+1.92+1.92 \\
R_{s}=4.15 \Omega
\end{gathered}
$$

The stack length $L$, Coil turns $N_{p h}$ and the diameter of the conductor $D_{c}$ are taken from Supplementary Table 1).

Armature Inductance is fixed at $H=2 X 10^{-6}$ Henry.

The flux linkage is calculated as;

$$
\text { Flux Linkage }=N_{p h} \times \varphi
$$

Where; flux per pole,

$$
\begin{aligned}
& \varphi=B_{g} \times \text { Area of one pole And, } \\
& \text { Area of one pole }=\tau_{p} \times L_{\text {stack }}
\end{aligned}
$$

$\tau_{p}$, is the pole pitch and $B_{g}$ is the air gap flux density,

Therefore, using Equation 3,

$$
\begin{gathered}
\text { Flux Linkage }=N_{p h} \times B_{g} \times \tau_{p} \times L_{\text {stack }} \\
=(60 \times 0.65 \times 38.039 \times 1094.81) /(1000 \times 1000) \\
\text { Flux Linkage, } \Psi=1.624 \text { Weber-turn }
\end{gathered}
$$

(values are taken from the Supplementary Table 1).

The number of poles calculated is:

$$
\begin{array}{r}
P=\frac{120 \times f(\mathrm{~Hz})}{N(\mathrm{rpm})} \ldots \\
\mathrm{P}=\frac{120 \times 50}{100}
\end{array}
$$

$\mathrm{P}=60$ poles

The number of slots $N_{s}$ is calculated as:

Since the number of slots per pole per phase $q=1$.

Therefore,

$$
\begin{gathered}
N_{s}=3 \times \text { Poles } \\
N_{s}=3 \times 60=180 \text { slots }
\end{gathered}
$$

The input parameters for the permanent magnet synchronous generator are given below:

$$
\begin{gathered}
\text { Resistance of the Stator } R s=4.15 \Omega \\
\text { Armature Inductance }(H)=2 \times 10^{-6} \text { henry } \\
\text { Flux linkage }=1.624 \text { Weber-turn } \\
\text { Pair of poles }=30
\end{gathered}
$$

\section{Sensitivity of the designed machine}

The Sensitivity of the designed machine about the flux linkage $\Psi$, the stator resistance $R_{s}$ and the armature inductance $H$ are considered. Figure 4, shows the Voltage measurement between terminals $\mathrm{A}$ and $\mathrm{B}$, which is about 400 Volts according to the PMSG parameters given in Table 5. It also shows the speed of the rotor which is according to the rated speed of $100 \mathrm{rpm}$. 


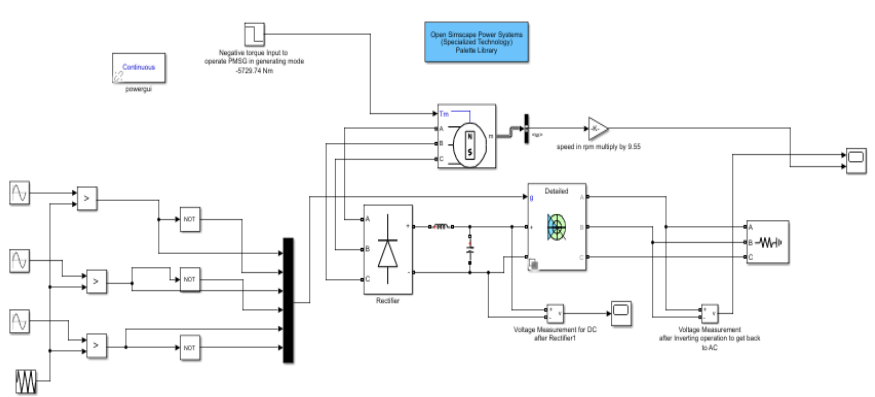

Figure 3: Matlab Simulink design of PMSG.

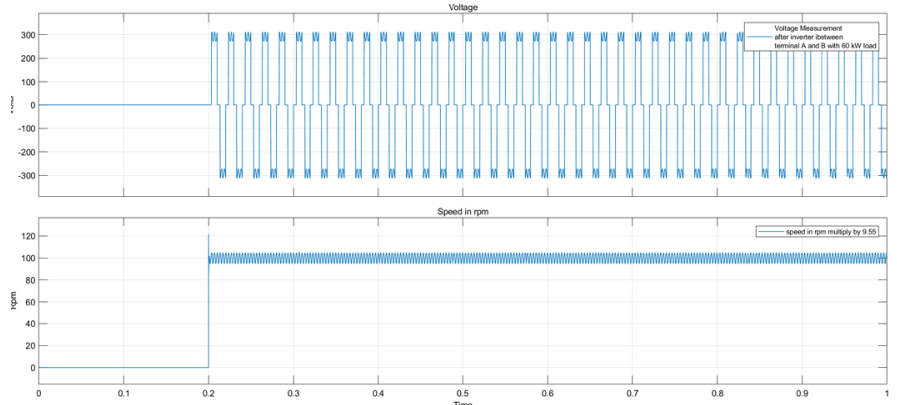

Figure 4: Voltage Measurement between terminal A and $B$ and Speed in rpm.

Table 2: Comparison of different types of generators (Gupta and Singh, 2016).

\begin{tabular}{llllll}
\hline $\begin{array}{l}\text { Genera- } \\
\text { tor type }\end{array}$ & $\begin{array}{l}\text { Energy } \\
\text { yield }\end{array}$ & Cost & $\begin{array}{l}\text { Relia- } \\
\text { bility }\end{array}$ & $\begin{array}{l}\text { Grid Sup- } \\
\text { portability }\end{array}$ & $\begin{array}{l}\text { Tech- } \\
\text { nical } \\
\text { Maturity }\end{array}$ \\
\hline SCIG & Least & Least & Highest & Least & Highest \\
WRIG & $\begin{array}{l}\text { Average } \\
\text { highest }\end{array}$ & Highest & & Highest & Highest \\
& & & &
\end{tabular}

DFIG Average Average Average Average Highest highest

PMSG Highest Average Average Highest Average highest highest highest

Table 3: Constant parameters (Madani et al., 2015).

\begin{tabular}{ll}
\hline Parameter names & Values in units \\
\hline Winding factor, $K_{w}$ & 0.866 \\
Tooth flux density, $B_{t}$ & $1.8 \mathrm{~T}$ \\
Remnant flux density, $B_{r}$ & $1.6 \mathrm{~T}$ \\
Stator flux density, $B_{s}$ & $1.6 \mathrm{~T}$ \\
Lamination filling factor, $K_{\text {fll }}$ & 0.45 \\
Electric loading AC & 25000 watt-hours \\
\hline
\end{tabular}

Variation of flux linkage and its effect on the output load voltage and speed while keeping other parameters constant By increasing the flux linkage from, a calculated value of 1.624 weber turns to 2.124 weber turns the voltage between terminal voltage and speed of the rotor decreases. It further decreases when the flux linkage is 2.624-weber turns. By decreasing the flux linkage from a nominal value of 0.624 weber-turns the speed of the rotor increases drastically while the voltage across the load between terminal $\mathrm{A}$ and $\mathrm{B}$ also increases. Constant and designed parameters of PMSG are shown in Table 3 and Table 4.

Table 4: Parameters of PMSG to be designed.

\begin{tabular}{|c|c|}
\hline Parameters & Value \\
\hline Pole number & 60 \\
\hline Slot number & 180 \\
\hline Number of phases & 3 \\
\hline Rated speed in rpm & 100 \\
\hline Rated output power (W) & $60 k W$ \\
\hline Rated Torque (N.m) & $5729.75 \mathrm{Nm}$ \\
\hline Induced Voltage (V) & 230 \\
\hline Estimated efficiency (\%) & $90 \%$ \\
\hline Winding turns per slot (turns) & 5 \\
\hline Stator radius: inner/outer $(\mathrm{m}) R_{s i}, R_{s}$ & $0.729 / 0.762$ \\
\hline Rotor radius: inner/outer $(\mathrm{m}) R_{r i}, R_{r}$ & $0.696 / 0.726$ \\
\hline Air-gap length $(\mathrm{m}) l_{g}$ & 0.0015 \\
\hline Magnet thickness $(\mathrm{m}) l_{m}$ & 0.001 \\
\hline Stack length (m) & 1.094 \\
\hline Slot Depth (m) & 0.011 \\
\hline Slot opening Width (m) & 0.00254 \\
\hline Tooth width $t_{w}(\mathrm{~m})$ & 0.00517 \\
\hline Core material/ Permanent magnet & N30AHNdFeB \\
\hline \multicolumn{2}{|c|}{ Parameters validated through Motor-solve software. } \\
\hline \multicolumn{2}{|l|}{ Table 5: PMSG parameters. } \\
\hline Name of the Parameter & Calculated value \\
\hline Flux Linkage $\Psi$ & 1.624 weber-turns \\
\hline Stator Resistance $R_{s}$ & $4.15 \mathrm{ohms}$ \\
\hline Armature Inductance $(H)$ & $2 \times 10^{-6} H$ \\
\hline
\end{tabular}

For flux linkage 2.124 weber-turns

Figure 5, shows voltage between terminal A and B when the flux linkage is increased to 2.124 weberturns. As we can see the voltage between the two terminals has decreased from the nominal value. It shows the speed of the rotor in rpm which is reduced to $60 \mathrm{rpm}$.

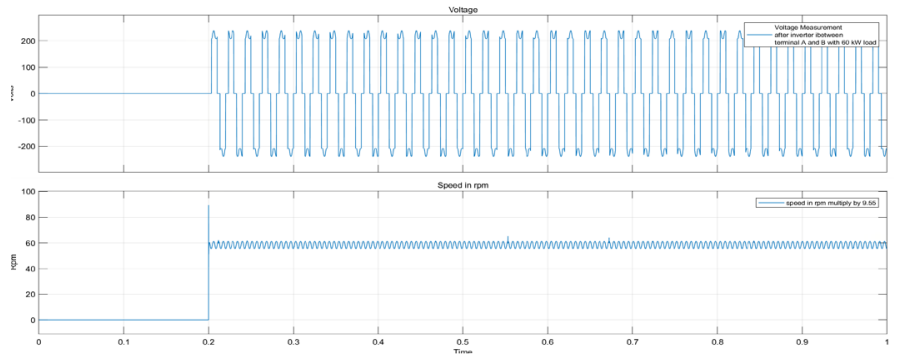

Figure 5: Voltage Measurement between terminal A and $B$ and Speed in rpm. 
For flux linkage 2.624 weber-turns

Figure 6, shows the voltage between terminal A and B when flux linkage is further increased to 2.624 weberturns, while the speed of the rotor in rpm when the flux linkage is increased to 2.624 weber-turns.

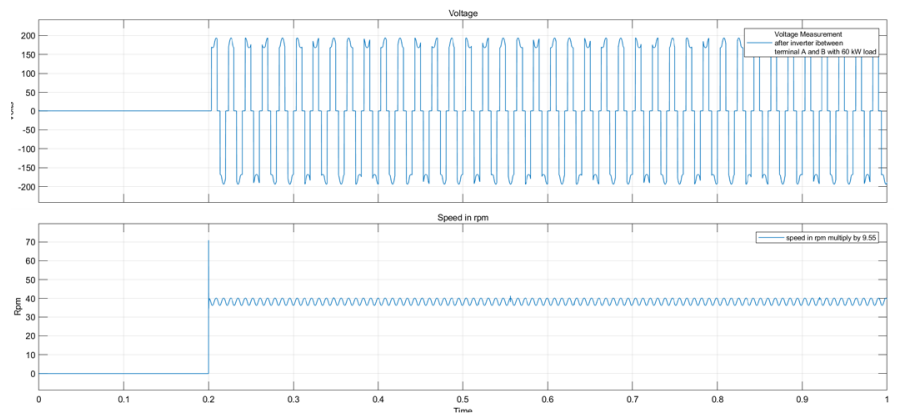

Figure 6: Voltage Measurement between terminal $A$ and $B$ and Speed in rpm.

\section{For flux linkage 0.624 weber-turns}

Figure 7, shows the voltage across the terminal A and $\mathrm{B}$ when flux linkage is reduced to 0.624 weber-turns while showing the speed of the rotor in rpm when the flux linkage is reduced to 0.624 weber-turns. The speed of the rotor has greatly increased to around 680 rpm.

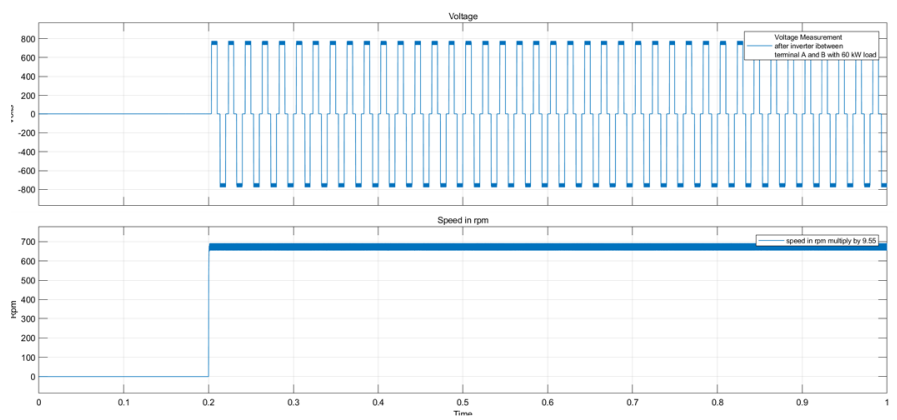

Figure 7: Voltage Measurement between terminal $A$ and $B$ and Speed in rpm.

Variation in stator resistance while keeping other parameters constant

On increasing the stator resistance from the calculated value of $4.15 \mathrm{ohms}$ to 4.65 and $5.14 \mathrm{ohms}$, the voltage between terminal $\mathrm{A}$ and $\mathrm{B}$ does not change much while the rotor speed in rpm slightly increases. On decreasing the stator resistance to $3.65 \mathrm{ohms}$, the rotor speed reduces from $100 \mathrm{rpm}$, while the voltage across the terminals remains unchanged.

\section{For Stator Resistance of 4.65 obms}

Figure 8 , shows the voltage between terminal $A$ and $B$ when the stator resistance is increased to $4.65 \mathrm{ohms}$, while it shows the speed of the rotor in rpm which shows an increment from the rated value.

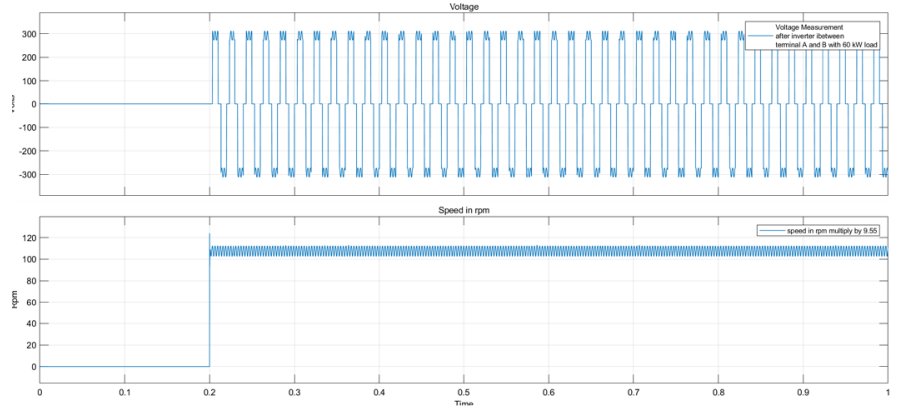

Figure 8: Voltage Measurement between terminal $A$ and $B$ and Speed in rpm.

For stator resistance of 3.65 obms

Figure 9, shows the voltage across the terminal A and $\mathrm{B}$ when the stator resistance is reduced to 3.65 ohms, while showing the rotor speed in rpm when the stator resistance is reduced to $3.65 \mathrm{ohms}$. It shows that speed in rpm to be slightly reduced by $90 \mathrm{rpm}$.

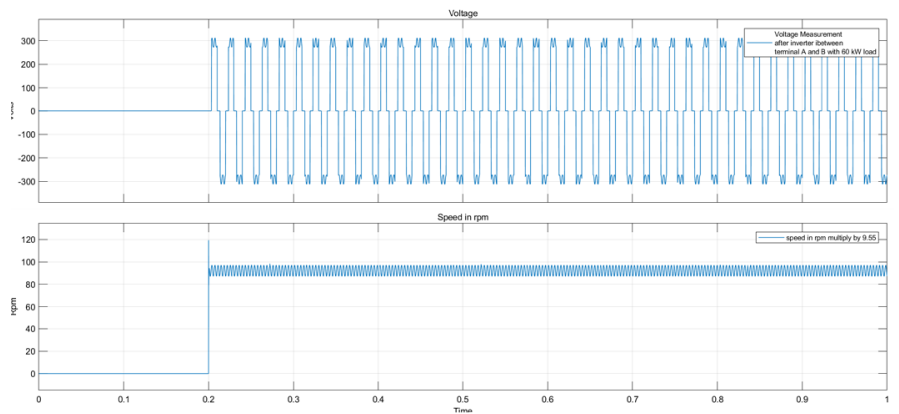

Figure 9: Voltage Measurement between terminal $A$ and $B$ and Speed in rpm.

For stator resistance of $5.15 \mathrm{ohms}$

Figure 10, shows the voltage across the terminal when the stator resistance is increased to $5.15 \mathrm{ohms}$, while it shows the speed in rpm when the stator resistance is set to 5.15 ohms. It shows that the speed is increased to $118 \mathrm{rpm}$.

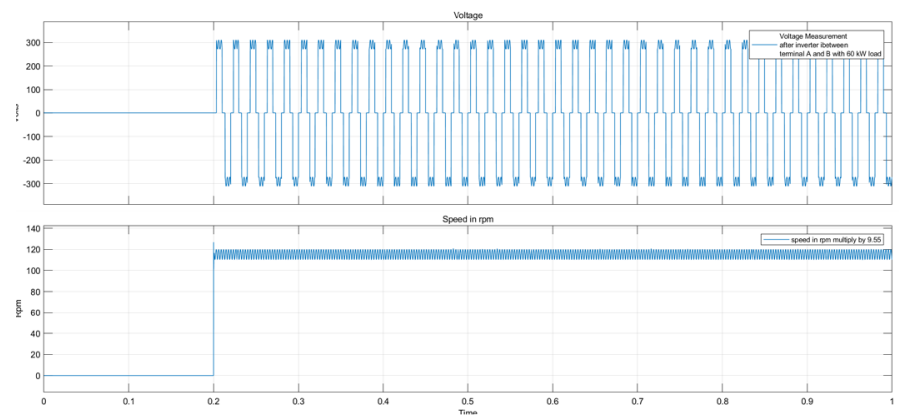

Figure 10: Voltage Measurement between terminal $A$ and $B$ and Speed in rpm.

Variation of armature inductance while keeping other parameters constant

On increasing the armature inductance from the June 2021 | Volume 40 | Issue 1 | Page 57 
calculated value of $2 \times 10^{-6} \mathrm{H}$ to $2 \times 10^{-5} \mathrm{H}$ and $2 \times 10^{-4} \mathrm{H}$ the voltage across the terminal does not change much while the rotor speed shows an abrupt increase at the step input of 0.2 and we can see disturbances along the line of $100 \mathrm{rpm}$. By decreasing the value from $2 \times 10^{-6} H$ to $2 \times 10^{-7} H$ and $2 \times 10^{-8} H$ the voltage across the terminal $\mathrm{A}$ and $\mathrm{B}$ rotor speed remains the same.

\section{For armature inductance of 2xexp-7 henry}

Figure 11, shows the voltage across the terminal when the armature inductance is set at $2 \times 10^{-7} \mathrm{H}$, while it shows the speed in $\mathrm{rpm}$ when the armature inductance is reduced to $2 \times 10^{-7} H$.

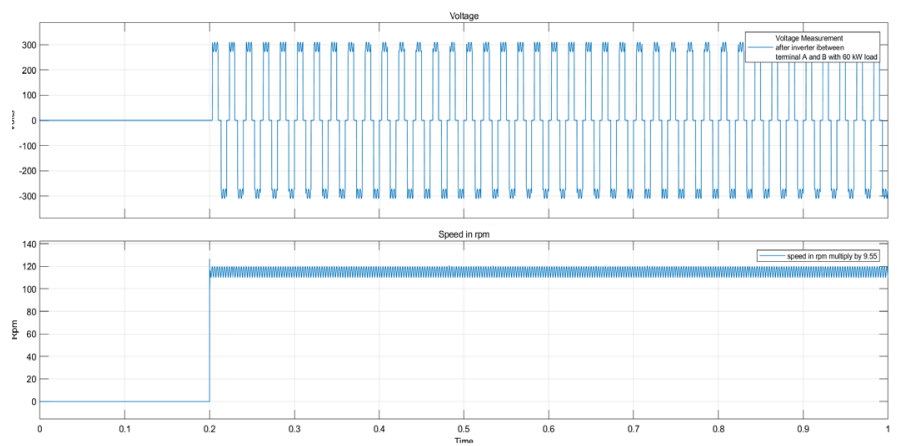

Figure 11: Voltage Measurement between terminal $A$ and $B$ and Speed in rpm.

\section{For armature inductance of $2 x e x p-8$ henry}

Figure 12, shows the voltage between terminal A and $\mathrm{B}$ when the armature inductance is further reduced to $2 \times 10^{-8} \mathrm{H}$, while it shows the speed in $\mathrm{rpm}$ when the armature inductance is set to $2 \times 10^{-8} \mathrm{H}$.

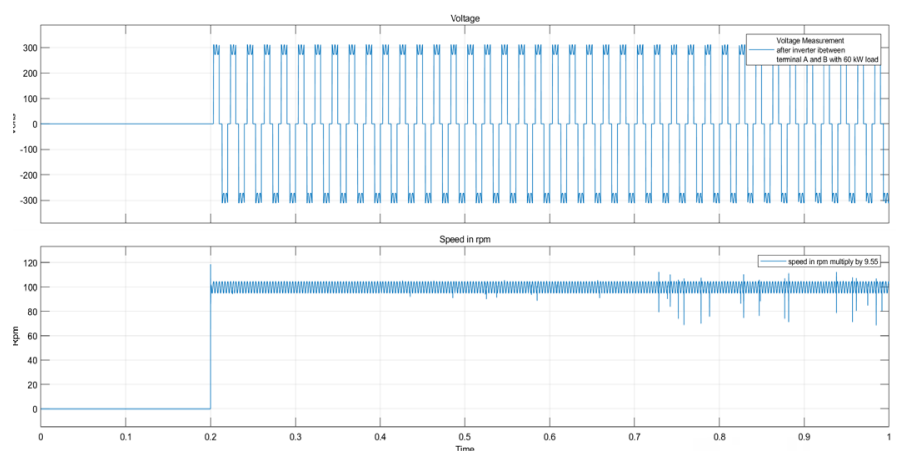

Figure 12: Voltage Measurement between terminal $A$ and $B$ and Speed in rpm.

For armature inductance of $2 x e x p-5$ benry

Figure 13, shows the voltage across the terminal A and $\mathrm{B}$ when the armature inductance is increased to $2 \times 10^{-5} \mathrm{H}$, while it shows the speed in rpm when the armature inductance is increased to $2 \times 10^{-5} \mathrm{H}$ from the nominal value. We can see a spike in rotor speed at step input of 0.2 .

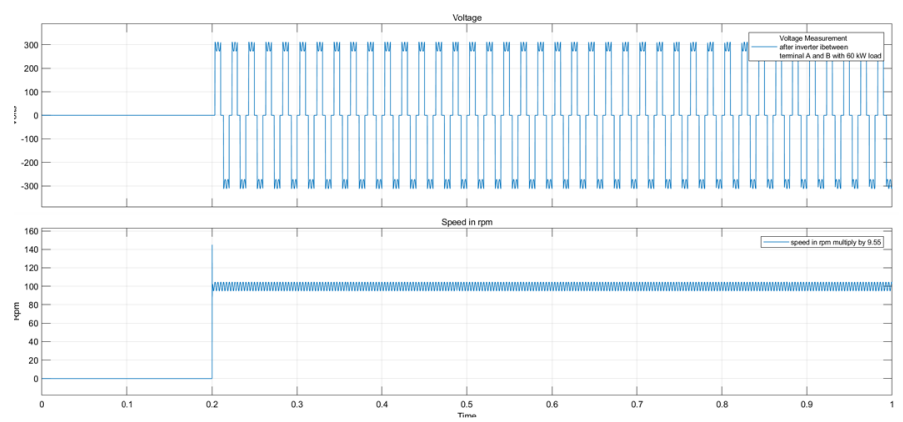

Figure 13: Voltage between terminal $A$ and $B$.

\section{For armature inductance of $2 x \exp -4$ henry}

Figure 14, shows the voltage across the terminal $\mathrm{A}$ and $\mathrm{B}$ when the armature inductance is further increased to $2 \times 10^{-4} H$, while it shows the rotor speed in rpm when the armature inductance is increased to $2 \times 10^{-4} H$.

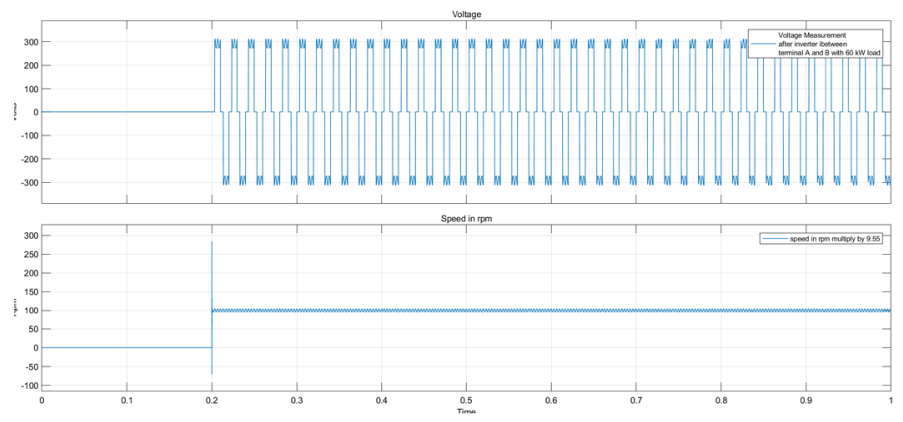

Figure 14: Voltage between terminal $A$ and $B$.

\section{Conclusions and Recommendations}

In low-income countries, harvesting energy from wind and solar is considered the most viable option to meet residential demand for a particular locality. However, the designed capacity of the generator could change with the increasing energy demand in different areas. Decentralizing the energy mix into smaller units is an option to lessen the burden on the national grid which will have an impact on reducing the usage of fossil fuels and minimize $\mathrm{CO}_{2}$ emissions. This paper brings an idea to the town planners and local developers of the power market that electricity can be fed to the residential communities from wind and solar while solving the two renewables' intermittency issues and giving better life quality for the community of that area.

\section{Novelty Statement}

The novelty of the design is based on modifying the slot dimensions until a difference in magnitude of area of slot calculated through iteration and area of 
slot evaluated by equation A_cs/K_fill reaches the minimum value of $5 \%$ of A_s (area of slot).

\section{Author's Contribution}

Shoaib Khan: Writing original draft

Sida Hussain: Rating/specification of wind generators.

Amir Naveed: Research methodology and guidance about wind energy

Nazia Wali: Reviewed and editing technically.

Zafar Ullah: Cross checked the results with published research data

Muhammad Arif: Project administration and Supervision

Muhammad Sadiq: Review of draft

Muhammad Asif: Review on analyz-ing simulation techniques.

\section{Supplementary Material}

There is supplementary material associated with this article. Access the material online at:

\section{Conflict of interest}

The authors have declared no conflict of interest.

\section{References}

Alrikabi, N.K.M.A., 2014. Renewable energy types. J. Clean Energy Technol., 2(1): 61-64. https://doi.org/10.7763/JOCET.2014.V2.92

Baloch, M.H., S.T. Chauhdary, D. Ishak, G.S. Kaloi, M.H. Nadeem, W.A. Wattoo, T. Younas and H.T. Hamid. 2019. Hybrid energy sources status of Pakistan: An optimal technical proposal to solve the power crises issues. Energy Strategy Rev., 24: 132-153. https://doi.org/10.1016/j. esr.2019.02.001

Beainy, A., C. Maatouk, N. Moubayed and F. Kaddah. 2016. Comparison of different types of generators for wind energy conversion system topologies.In: $20163^{\text {rd }}$ International Conference on Renewable Energies for Developing Countries (REDEC). IEEE. pp. 1-6. https:// doi.org/10.1109/REDEC.2016.7577535

Chiari, L. and A. Zecca. 2011. Constraints of fossil fuels depletion on global warming projections. Energy Policy, 39(9): 5026-5034. https://doi.org/10.1016/j.enpol.2011.06.011
Ghoneim, W.A., A. Hebala and H. Ashour. 2016.

A comparative study of winding configuration effect on the performance of low speed PMSG using FEM. In: $201618^{\text {th }}$ International Middle East Power Systems Conference (MEPCON). IEEE. pp. 348-352. https://doi.org/10.1109/ MEPCON.2016.7836914

Gupta, N. and Y. Singh. 2016. Optimal selection of wind power plant components using technique for order preference by similarity to ideal solution (Topsis). In: 2016 International Conference on Electrical Power and Energy Systems (ICEPES).IEEE.pp.310-315. https:// doi.org/10.1109/ICEPES.2016.7915949

Hebala, A., W.A. Ghoneim and H.A. Ashour. 2017. Different design approaches of surface mounted high performance PMSG. In: 2017 International Conf on Advanced Control Circuits Systems (ACCS) Systems and 2017 Intl Conf on New Paradigms in Electronics and Information Technology (PEIT) IEEE. pp. 85-90. https://doi.org/10.1109/ACCSPEIT.2017.8303024

Herbert, G.J., S. Iniyan, E. Sreevalsan and S. Rajapandian. 2007. A review of wind energy technologies. Renewable Sustain. Energy Rev., 11(6): 1117-1145. https://doi. org/10.1016/j.rser.2005.08.004

Madani, N., A. Cosic and C. Sadarangani. 2015. A permanent magnet synchronous generator for a small scale vertical axis wind turbine. In: 2015 IEEE International Electric Machines and Drives Conference (IEMDC). IEEE. pp. 48-52. https://doi.org/10.1109/ IEMDC.2015.7409035

Patil, N.S. and Y.N. Bhosle. 2013. A review on wind turbine generator topologies. In: 2013 International Conference on Power, Energy and Control (ICPEC). IEEE. pp. 625-629. https:// doi.org/10.1109/ICPEC.2013.6527733

Saleem, L. and I. Ulfat. 2019. A multi criteria approach to rank renewable energy technologies for domestic sector electricity demand of Pakistan. Mehran Univ. Res. J. Eng. Technol., 38(2): 443-452. https://doi. org/10.22581/muet1982.1902.18

Shafiee, S. and E. Topal. 2009. When will fossil fuel reserves be diminished? Energy Policy, 37(1): 181-189. https://doi.org/10.1016/j. enpol.2008.08.016 